\title{
Effects of Undernutrition and Predictors on the Survival Status of HIV-Positive Children after Started Antiretroviral Therapy (ART) in Northwest Ethiopia
}

\author{
Mulugeta Molla, ${ }^{1}$ Fassikaw Kebede $\mathbb{D}^{2},{ }^{2}$ Tsehay Kebede $\mathbb{D}^{3},{ }^{3}$ and Assefa Haile ${ }^{4}$ \\ ${ }^{1}$ Pharmacology and Toxicology Unit, Department of Pharmacy, College of Health Sciences, Debre Tabor University, \\ Debre Tabor, Ethiopia \\ ${ }^{2}$ Department of Epidemiology and Biostatistics, School of Public Health, College of Health Science, Woldia University, \\ Woldia, Ethiopia \\ ${ }^{3}$ Department of Geography and Environmental Study, Faculty of Social Science, Bahir Dar University, Bahir Dar, Ethiopia \\ ${ }^{4}$ Department of Nursing and Midwifery, Pawe Health Science College, Metekel Zone, Pawe Woreda North West, Ethiopia \\ Correspondence should be addressed to Fassikaw Kebede; fassikaw123@gmail.com
}

Received 18 October 2021; Revised 14 January 2022; Accepted 4 February 2022; Published 17 February 2022

Academic Editor: Samuel Menahem

Copyright (C) 2022 Mulugeta Molla et al. This is an open access article distributed under the Creative Commons Attribution License, which permits unrestricted use, distribution, and reproduction in any medium, provided the original work is properly cited.

\begin{abstract}
Malnutrition and human immunodeficiency virus/acquired immunodeficiency syndrome have complex and multidirectional relationships. Ethiopia is one of the countries hardest hit by the HIV epidemic as well as malnutrition. This study was aimed at assessing the effects of undernutrition on the survival status of HIV-positive children who received HIV/AIDS care in Northwest Ethiopia. Materials and Methods. A facility-based retrospective follow-up was conducted from January 1, 2009, to December 31, 2020. The data was entered into EpiData version 4.2.0. Then, the entered data was exported to STATA 14 software for further analysis, and the Kaplan-Meier survival curve was used to estimate survival time after the initiation of ART. The Bivariable and multivariable Cox regression analyses were conducted to identify predictors of mortality associated with undernutrition. Results. The mean $( \pm \mathrm{SD})$ age of participant children was found $118.4( \pm 38.24)$ months. The overall mortality rate in this study was determined as 5.4 per 100 child-years (95\% CI: 3.6, 5.8). Children with CD4 cell counts below the threshold $[\mathrm{AHR}=1.6 ; 95 \%$ CI $(1.19,7.85)$ ], advanced WHO clinical stages (III and IV) HIV [AHR $=4.5 ; 95 \%$ CI $(2.80$, $8.40)]$, and being severe stunting at the beginning $[\mathrm{AHR}=2.9 ; 95 \% \mathrm{CI}(1.80,6.40)]$ were significantly associated with mortality of HIV-positive children. Conclusion. The findings of the current study indicated that HIV-positive children on ART had a high rate of mortality. Baseline undernutrition has the mortality of children who had CD4 counts below a threshold, advanced WHO HIV clinical staging (III and IV), and being severe stunting (HAZ $\leq-3 \mathrm{Z}$ score) which were found to be independent predictors for mortality of undernourished HIV.
\end{abstract}

\section{Introduction}

Malnutrition and human immunodeficiency virus (HIV)/ acquired immunodeficiency syndrome (AIDS) have complex and multidirectional relationships that cause progressive immune system damage [1]. Both are frequently intertwined and have a synergistic effect [2]. Malnutrition increases viral replication and accelerates the progression of HIV disease by decreasing CD4 T cells, suppressing delayed hypersensitivity, and altering $\beta$-cell responses $[3,4]$. For this reason, malnutrition has a poor prognosis for clinical outcomes [5]. However, HIV/AIDS accelerates the progression of immune impairment and the occurrence of opportunistic infections [6] by increasing the risk of appetite loss, hastening the decline of $\mathrm{CD} 4 \mathrm{~T}$ cell concentration, and causing markers of microbial translocation (16sDNA), intestinal damage (iFABP), monocyte activation, and increased proteolysis in HIV-positive children [6-10]. Children with HIV/AIDS have a reduced 
appetite and ability to consume food, as well as a higher incidence of diarrhea, resulting in malabsorption and nutrient a loss, which makes malnutrition a common phenomenon $[11,12]$. In 2018, an estimated 1.7 million children (aged $<15$ years) were living with HIV worldwide $[13,14]$. In the same year, in Ethiopia, 44229 children were diagnosed with HIV and 2055 died related to AIDS [9, 15]. Undernutrition in all its forms remains a global public health burden that accounts for $45 \%$ of all deaths for people living with HIV $[2,16]$. Children are more vulnerable to undernutrition than adults with HIV; hence, rapid viral replication and a higher rate of CD4 cell destruction are inevitable due to immature immunity [17]. Evidence suggests that even relatively small losses in weight $(5 \%)$ are associated with a decrease in the survival rate of HIV-positive children [18]. Epidemiologically, the incidence of stunting is declining too slowly, while wasting still has a great impact on too many young children worldwide [19]. In 2017, 13.8 million children were wasted, of whom 4 million were severely wasted $[13,20]$. Most of all were in sub-Saharan countries [21]. Each year, over a million children die and develop severe acute malnutrition (SAM), and it presents mainly in marasmus, kwashiorkor, or marasmus kwashiorkor $[22,23]$. Similarly, in comparison to kwashiorkor, wasting was more commonly reported [8, $24]$, as was early bone growth failure and an increased risk of death in HIV-positive children [1, 25].

Several studies investigated whether lower CD4 cell count, age, wealth index, adherence, food insecurity, and social support were risk factors for malnourished HIVpositive children's mortality $[1,2,15,26-28]$. Ethiopia is one of the countries hardest hit by the HIV epidemic as well as malnutrition [1]; the prevalence of undernutrition among HIV/AIDS children ranges from 12.3 to $46.8 \%[19,29]$ and is blamed for $57 \%$ of deaths $[6,13]$. However, evidence of the effect of undernutrition on the survival status of HIVpositive children who are $<15$ years of age remains sparse and inconclusive $[11,29]$. This study aims to assess the effects of undernutrition and its predictors on the survival of HIV-positive children who received antiretroviral therapy (ART) in selected public health facilities in Northwest Ethiopia.

\section{Materials and Methods}

2.1. Study Design and Setting. A facility-based retrospective follow-up study was employed among $721 \mathrm{HIV}$-positive children who started HIV/AIDS care in two hospitals and two health centers since January 1, 2009, to December 31, 2020, which are representative of the Benishangul-Gumuz region. All these health facilities provide health care services for all Oromia, Amhara, and Benishangul regions [30]. Following HIV/AIDS care initiated in the regions between January 1, 2009, and December 31, 2020, there were $2968 \mathrm{HIV} /$ AIDS care started populations. More than 737 of these populations were children living with HIV/AIDS, and the data were drawn from two hospitals and two health centers (Assosa Hospital $N=359$ and Pawe Hospital $N=315$; Felege Selam Health Center $N=21$ and Gilgel Beles Health Center $N=37$ ) which were included for the final data analysis.
2.2. Populations. The records of all HIV-infected children, whoever started ART in four health institutions, were the source of the population. The records of all HIV-infected children receiving ART between January 1, 2009, and December 31, 2020, were considered as the study population. All HIV-infected children who had at least one month of ART follow-up from January 1, 2009, to December 31, 2020, were included.

\subsection{Sample Size Determination and Sampling Techniques.}

The sample size was calculated by using the formula [31] for survival analysis by considering two-sided significance level $(\alpha=5 \%), Z \alpha / 2=\mathrm{Z}$ value at 95\%confidence interval $=$ 1.96, power $(\mathrm{Z} \beta)=80 \%$, and $P=\%$ cumulative occurrence of death rate, $1.65 \mathrm{HR}$.

The final sample size $(N)=E=\left(Z \alpha_{/ 2} \pm Z \beta\right)^{2}=(Z \alpha / 2+$ $Z \beta)$,

$$
\begin{gathered}
P(E) \quad \theta^{2} p(1-p), \quad p(1-\mathrm{p})(\ln \mathrm{HR})^{2}, \\
\theta=\ln (\mathrm{HR}), \\
\mathrm{HR}=\mathrm{e}^{\theta},
\end{gathered}
$$

where $\alpha=0.05, \beta=0.2, \mathrm{HR}=$ hazard ratio, $N=$ sample size, $E=$ number of events, $P(E)=$ probability of event, and $P=$ cumulative occurrence of treatment failure, used as reference for sample size calculation [32]. The final sample size was determined as 512.5 after adding a 15\% contingency for incompleteness. From January 1, 2009, to December 31, 2020, in four health institution there were totaly 738 recoded chartes of HIV infected children; while with outany sampling procedure we included all 738 files, since it is manageable by resource and human poweres for stastical analysis and increases stastical inferen.

2.4. Outcome Ascertainment. The outcome variable for this study is the death of HIV-positive children after starting HIV/AIDS care. Death is defined as when the child has approved records of death in his/her treatment follow-up medical records after initiating HIV/AIDS care from January 1,2009 , to December 31,2020 , where it is not due to accidental unrelated causes. Those records or ART clients who did not develop the outcome (death) at the end of the study are called censored cases.

2.5. Independent Variables. The independent variables were sociodemographic, clinical, and medication-related variables, as well as nutritional. Sociodemographic variables included age and sex of children, caregivers' age and residence, marital status of the caregiver, family size, caregivers' relationship to the child, and religion. Baseline clinical and hematologic variables included the World Health Organization (WHO) clinical staging, CD4 count, hemoglobin, and opportunistic infections. ART-related variables included regimen, duration of ART, regimen change, treatment failure, isoniazid preventive therapy (IPT), cotrimoxazole preventive therapy (CPT), and adherence status of ART. Nutritional status included weight for age (W/age), height for age (H/age), and weight for height $(\mathrm{W} / \mathrm{H})$. 


\subsection{Operational Definitions}

2.6.1. Severe Acute Malnutrition (SAM). According to the $\mathrm{WHO}$, children under the age of 59 months who have a weight-for-height ratio of $\leq-3 \mathrm{Z}$ score, a mid-upper arm circumference of $<15 \mathrm{~cm}$, bilateral edema, and a failed appetite test should be admitted for inpatient care [33].

2.6.2. Undernutrition. Undernutrition was defined as a child having one of the following descriptions: WFA Z score $<-2$ or HFA Z score $<-2$ or WFH Z score $<-2$ SD $[3,13]$.

2.6.3. Nutritional Status. A well-nourished child had a W/ age $\mathrm{Z}$ score $>-2, \mathrm{H}$ /age $\mathrm{Z}$ score $>-2$, or $\mathrm{W} / \mathrm{H} \mathrm{Z}$ score $>-2$ $\mathrm{SD}$ and/or mid-upper arm measurement (MUAC $>11.5 \mathrm{~cm}$ ) with no pathological or physiological grading edema [6].

2.6.4. CD4 Count. CD4 below the threshold level was classified based on the age of the child (i.e., infants CD $4<1500$ $/ \mathrm{mm}^{3}, 12-35$ months $<750 / \mathrm{mm}^{3}, 36-59$ months $<350 /$ $\mathrm{mm}^{3}$, and $\geq 5$ years $<200 / \mathrm{mm}^{3}$ ) [23].

2.6.5. ART Adherence. ART adherence for pediatrics is classified based on the percentage of drug dosage calculated from the total monthly doses of ART drugs: good $>95 \%$, fair $=85-94 \%$, and poor $<85 \%[34]$.

2.7. Data Collection Instruments. Before the data collection procedure was deployed for children, the standard anthropometric measurements were taken from all subjects at recruitment and at follow-up after being discharged from the clinic. MUAC was measured using a color-coded MUAC tape on the left arm. Data abstraction tools (checklists) were prepared using Ethiopia's Federal Ministry of Health Pediatrics ART follow-up and medical history sheet combination [35]. Six diploma nurses and four BSc public health officers were recruited for data collection and supervision. One day of training was given for data collection and supervision for all facility data collectors.

2.8. Data Collection Procedures and Quality Assurance. To assure the quality of the data, data collectors and supervisors were trained about how and what information they should collect from the medical records for one day. The checklist was pretested on 5\% of randomly chosen charts that were not included in the actual study. After the pretest, the necessary modifications to the data collection tool were made. Strict follow-up and supervision were carried out during data collection by the principal investigator, and feedback was given daily. Individual records with incomplete data during data collection were excluded. The collected data was first checked and cleaned for completeness.

2.9. Data Processing and Analysis. Following data collection and quality assurance, the questionnaire was coded and the data entered into EpiData version 4.2.0. Then, the entered data was exported to STATA 14 software and used for analysis. The proportional hazard assumption was checked for each variable, and no variable was found with a Schoenfeld residual test $<0.05$. The Kaplan-Meier survival curve was used to estimate the survival time after the initiation of
ART, and log-rank tests were used to compare the survival curves. Accordingly, the final Cox regression model was fitted based on final step selected variables after model assumption, and three variables were associated with undernutrition-related mortality of HIV-positive children with $95 \% \mathrm{CI}$ at $P<0.05$ and claimed as the predictor for death [36].

\section{Results}

3.1. Sociodemographic Characteristics of Both HIV-Positive Children and Caregivers. Out of 732 records, 721 were included, resulting in a response rate of $98.50 \%$. About half of the $384(53.26 \%)$ were females. The largest percentage of children was categorized under the age group of $\geq 121$ months, which accounted for 389 (53.96\%) of the total subjects, with a mean $( \pm \mathrm{SD})$ age of $118.4 \pm 38.24$ months. The majority $510(70.74 \%)$ of children living with HIV were in urban residences. The majority, 498 (69.07\%), of caregivers were married, while their mean \pm SD was $58.1 \pm 18.6$ years. Regarding the family size of the caregivers, 227 (31.48\%), $462(64.08 \%)$, and $32(4.44 \%)$ of the HIV-positive children had less than two, three to five, and more than five family sizes, respectively. More than two-thirds (76.28\%) of the children's caregivers were HIV-positive. Furthermore, 381 (52.84\%), 337 (46.74\%), and 381 (52.84\%) of child caregivers were Orthodox religious believers and merchants by occupation, and both parents were alive, respectively (Table 1).

3.2. Clinical Characteristics of Study Participants. One hundred twenty-eight (17.75\%) of the 721 children were diagnosed with SAM and hospitalized for inpatient therapy. More than one-third of the cases $(35.78 \%)$ had at least one form of opportunistic infection before starting ART. The majority of children, 293 (40.64\%), were on AZT-3TC$\mathrm{NVP}$ of the ART regimen. In terms of adherence to ART at the time of the most recent ART visit, 356 (49.38\%) of the participants had good adherence, whereas $188(26.07 \%)$ of them had poor adherence. During enrollment in chronic HIV care, 237 (32.87\%) and 202 (28.02\%) of children on ART were on WHO stages I and II, respectively, while the remaining $282(39.11 \%)$ cases were on stages III and IV. A majority, 451 (62.55\%) and $419(58.11 \%)$, received isoniazid preventive therapy and cotrimoxazole preventive therapy, respectively. More than a third of the children, 308 (42.72\%), had CD4 counts below the threshold for severe immunodeficiency. Two hundred ninety-five (40.92\%) cases had 37-72 months of follow-up (Table 2).

3.3. Nutritional Status of the Study Participants. At baseline, approximately one-fifth of the participants (19.97\%) were moderately underweight, $21.36 \%$ were moderately stunted, and $16.50 \%$ were moderately wasted. Furthermore, the proportions of presenting child malnutrition cases were classified as severe underweight (11.93\%), severe stunting (19.28\%), and severe wasting (9.85\%) (Table 3).

3.4. Survival Status of HIV-Positive Children. The study participants were followed for 20116.845 person per month (PMOS) of risk observation within a median follow-up 
TABLE 1: Sociodemographic characteristics of HIV-positive children attending ART care in selected public health facilities in Northwest Ethiopia, January 1, 2009-December 30, 2020.

\begin{tabular}{|c|c|c|c|}
\hline Variables & Categories & Frequency & Percent \\
\hline \multirow[t]{2}{*}{ Sex } & Female & 384 & 53.26 \\
\hline & $\geq 5$ years & 78 & 10.81 \\
\hline \multirow[t]{2}{*}{ Age of children } & $6-10$ & 254 & 35.23 \\
\hline & $\geq 11$ years & 389 & 53.96 \\
\hline HIV disclosure status of children & Disclosed & 158 & 21.91 \\
\hline Age of caregivers & $\leq 45$ years & 244 & 33.84 \\
\hline Resident & Urban & 510 & 70.74 \\
\hline \multirow{4}{*}{ Marital status of the caregiver } & Single & 115 & 15.95 \\
\hline & Married & 498 & 69.07 \\
\hline & Divorced & 82 & 11.37 \\
\hline & Widowed & 26 & 3.61 \\
\hline \multirow{3}{*}{ Family size of caregivers } & $\leq 2$ & 227 & 31.48 \\
\hline & $3-5$ & 462 & 64.08 \\
\hline & $\geq 6$ & 32 & 4.44 \\
\hline \multirow{3}{*}{ HIV status of caregivers } & Positive & 550 & 76.28 \\
\hline & Negative & 91 & 12.62 \\
\hline & Unknown & 80 & 11.10 \\
\hline \multirow{4}{*}{ Religion of caregivers } & Orthodox & 381 & 52.84 \\
\hline & Muslim & 152 & 21.08 \\
\hline & Protestant & 139 & 19.28 \\
\hline & Catholics & 49 & 6.80 \\
\hline \multirow{4}{*}{ Occupational status of caregivers } & Farmer & 99 & 13.73 \\
\hline & Merchant & 337 & 46.74 \\
\hline & Employer & 124 & 17.20 \\
\hline & Laborer worker & 161 & 22.33 \\
\hline \multirow{4}{*}{ Parental status of children } & Both alive & 381 & 52.84 \\
\hline & Paternal orphan & 135 & 18.72 \\
\hline & Maternal orphan & 108 & 14.99 \\
\hline & Both orphaned & 97 & 13.45 \\
\hline \multirow{5}{*}{ Income class of caregiver } & First quintile & 288 & 39.94 \\
\hline & Second quintile & 123 & 17.06 \\
\hline & Third quintile & 85 & 11.79 \\
\hline & Fourth quintile & 119 & 16.51 \\
\hline & Fifth quintile & 106 & 14.70 \\
\hline
\end{tabular}

period of 23.56 months (IQR $= \pm 13.3$ months). At this instant, $30(4.2 \%)$ cases had died, with a median survival rate of 0.94 (95\% CI: 0.91, 0.96). At the end of follow-up, 394 (54.62\%) were currently on follow-up, whereas the remaining $212(29.40 \%), 14(1.94 \%)$, and 90 (12.48\%) were gone up on adult cohort, abscond, and decease, respectively. The mean survival time of the entire follow-up was 28.49 months (95\% CI: 26.7, 59.5). The cumulative probabilities of survival rate at four, eight, $16,24,48$, and 72 months after the initiation of ART were 0.99, 0.98, 0.97, 0.94, 0.71, and 0.49, respectively. The overall mortality rate in this study was determined as 5.4 per 100 child-years (95\% CI: 3.6, 5.8).

3.5. Log-Rank Estimate of Mortality and Comparison of Death Hazard. The Kaplan-Meier survival curve together with the log-rank test shows differences in the hazards of death or undernutrition in HIV-positive children on different covariates. Being $\mathrm{HIV}$-infected children at baseline stunting ( $H A Z \leq-3 \mathrm{Z}$ score), being on WHO clinical stage (III and IV), and having CD4 count below threshold had survival differences between undernourished and counter peers do have (Figures 1-3).

3.6. Bivariable and Multivariable Cox Regression Analysis. As shown in Table 4 in the multivariable Cox regression analysis, after adjustment and controlling of certain confounding in the final model, three variables were found significantly associated with mortality of undernourished children. HIV positive children with CD4 cell counts below the threshold were 1.6 times at higher risk of death as 
TABLE 2: Clinical and immunological profiles of HIV-positive children who received ART care in selected public health facilities in Northwest Ethiopia, January 1, 2009-December 30, 2020.

\begin{tabular}{|c|c|c|c|}
\hline Variables & Categories & Number & Frequency \\
\hline Dietary counseling during follow-up & Yes & 465 & 64.49 \\
\hline Admission history of SAM & Yes & 128 & 17.75 \\
\hline Opportunistic infections at baseline & Yes & 258 & 35.78 \\
\hline \multirow{8}{*}{ ART regimen types } & D4T-3TC-NVP & 48 & 6.66 \\
\hline & D4T-3TC-EFV & 26 & 3.61 \\
\hline & AZT-3TC-NVP & 293 & 40.64 \\
\hline & AZT-3TC-EFV & 165 & 22.88 \\
\hline & TDF-3TC-EFV & 104 & 14.42 \\
\hline & AZT-3TC-LPV/R & 36 & 4.99 \\
\hline & ABC-3TC-NVP & 25 & 3.47 \\
\hline & ABC-3TC-EFV & 24 & 3.33 \\
\hline \multirow[t]{2}{*}{ ART regimen change } & Yes & 211 & 29.26 \\
\hline & Appropriate & 68 & 71.58 \\
\hline \multirow[t]{3}{*}{ Functional status (age $\leq 5$ years) } & Delay & 15 & 15.79 \\
\hline & Regression & 12 & 12.63 \\
\hline & Working & 488 & 77.96 \\
\hline \multirow[t]{3}{*}{ Developmental history (age $>5$ years) } & Ambulatory & 87 & 13.89 \\
\hline & Bedridden & 51 & 8.15 \\
\hline & Good & 356 & 49.38 \\
\hline \multirow[t]{3}{*}{ Adherence } & Fair & 177 & 24.55 \\
\hline & Poor & 188 & 26.07 \\
\hline & I & 237 & 32.87 \\
\hline \multirow{3}{*}{ WHO clinical stage } & II & 202 & 28.02 \\
\hline & III & 170 & 23.58 \\
\hline & IV & 112 & 15.53 \\
\hline Isoniazid preventive therapy & Yes & 451 & 62.55 \\
\hline Cotrimoxazole preventive therapy & Yes & 419 & 58.11 \\
\hline $\mathrm{CD} 4$ count & Below the threshold & 308 & 42.72 \\
\hline \multirow[t]{3}{*}{ Hemoglobin level } & $\leq 10 \mathrm{~g} / \mathrm{dl}$ & 229 & 31.76 \\
\hline & Immunologic & 81 & 11.23 \\
\hline & Clinical stage & 96 & 13.31 \\
\hline \multirow[t]{7}{*}{ ART eligibility criteria } & WHO clinical stage & 79 & 10.96 \\
\hline & CD4 threshold & 199 & 27.60 \\
\hline & Examine and treat & 266 & 36.90 \\
\hline & Bacterial pneumonia & 79 & 30.62 \\
\hline & Diarrhea & 74 & 28.68 \\
\hline & Meningitis & 9 & 3.49 \\
\hline & Pneumocystis pneumonia & 6 & 2.32 \\
\hline \multirow[t]{6}{*}{ Type of opportunistic infection } & Skin dermatitis & 7 & 2.71 \\
\hline & Kaposi’s sarcoma & 5 & 1.94 \\
\hline & Acute/chronic otitis media & 9 & 3.49 \\
\hline & Others & 3 & 1.16 \\
\hline & Tuberculosis & 66 & 25.59 \\
\hline & $\leq 36$ months & 223 & 30.93 \\
\hline \multirow[t]{2}{*}{ Duration of ART } & $37-72$ months & 295 & 40.92 \\
\hline & $>72$ months & 203 & 28.15 \\
\hline Maternal PMTC follow-up history & Yes & 487 & 67.55 \\
\hline MUAC & $\leq 11.5 \mathrm{~cm}$ & 270 & 37.45 \\
\hline
\end{tabular}


TABLE 2: Continued.

\begin{tabular}{lccc}
\hline Variables & Categories & Number & Frequency \\
\hline Tuberculosis treatment history & Yes & 66 & 9.15 \\
Survival status of children & Died & 87 & 12.07 \\
\hline
\end{tabular}

TABLE 3: Nutritional status of HIV-positive children who received ART care in selected public health facilities of Northwest Ethiopia 20092020 .

\begin{tabular}{lccc}
\hline Variables & Categories & Frequency & Percent \\
\hline & Normal & 491 & 68.10 \\
Underweight (W/age) & Moderate underweight (WAZ $\leq-2)$ & 144 & 19.97 \\
& Severe underweight (WAZ $\leq-3)$ & 46 & 11.93 \\
& Normal & 59.36 \\
Stunting (H/age) & Moderate stunting (HAZ $\leq-2$ Z score) & 154 & 139 \\
& Severe stunting (HAZ $\leq-3$ Z score) & 531 & 19.28 \\
& Normal & 119 & 73.65 \\
Wasting $(\mathrm{W} / \mathrm{H})$ & Moderate wasting (WHZ or BAZ $\leq-2)$ & 71 & 9.85 \\
& Severe wasting (WHZ or BAZ $\leq-3)$ &
\end{tabular}

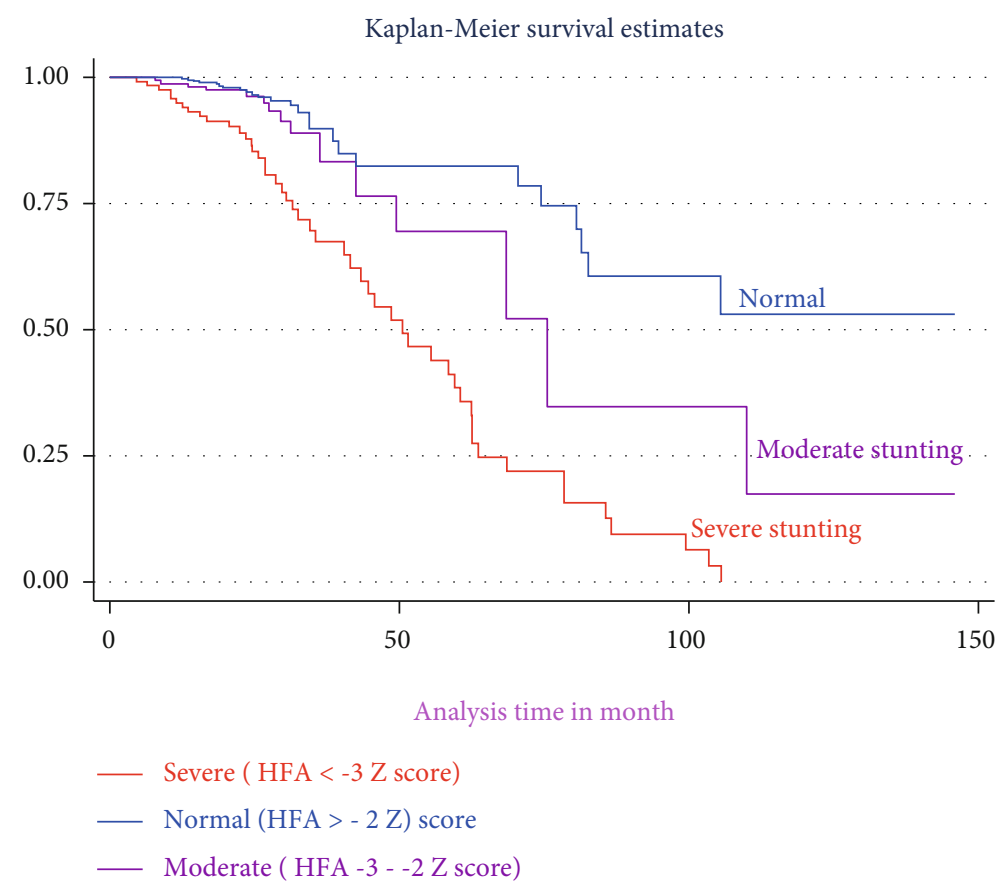

FIgURE 1: The Kaplan-Meier survival curves comparing the survival times of HIV-positive children on ART with different categories of stunting among selected public health facilities in Northwest Ethiopia from January 1, 2009, to December 30, 2020.

compared to cohort members above the threshold [AHR $=1.6 ; 95 \% \mathrm{CI},(1.19,7.85)]$. In the current study, WHO HIV clinical stages were found to be another predictor of mortality. Children with advanced WHO HIV clinical stages (III and IV) had a 4.5 times higher risk of death as compared to those with WHO HIV clinical stages (I and II) $[\mathrm{AHR}=4.5 ; 95 \% \mathrm{CI}(2.80,8.40)]$. The presence of severe stunting at the beginning of ART was associated with a 2.9 times higher risk of death than nonstunting cases $[$ AHR $=2.9 ; 95 \%$ CI $(1.80,6.40)]$ (Table 4$)$.

\section{Discussion}

In this retrospective cohort study, the effects of undernutrition and its predictors for survival status among HIVpositive children on ART were determined. At the end of chronic successive follow-up, about 90 (12.48\%) patients were deceased, and 14 (1.94\%) patients were absconded. The review data on the national level revealed a mortality rate of 5 to $8 \%$ at 6 months and 24 months after ART started $[11,23]$. The overall mortality rate of this study was 5.4 per 


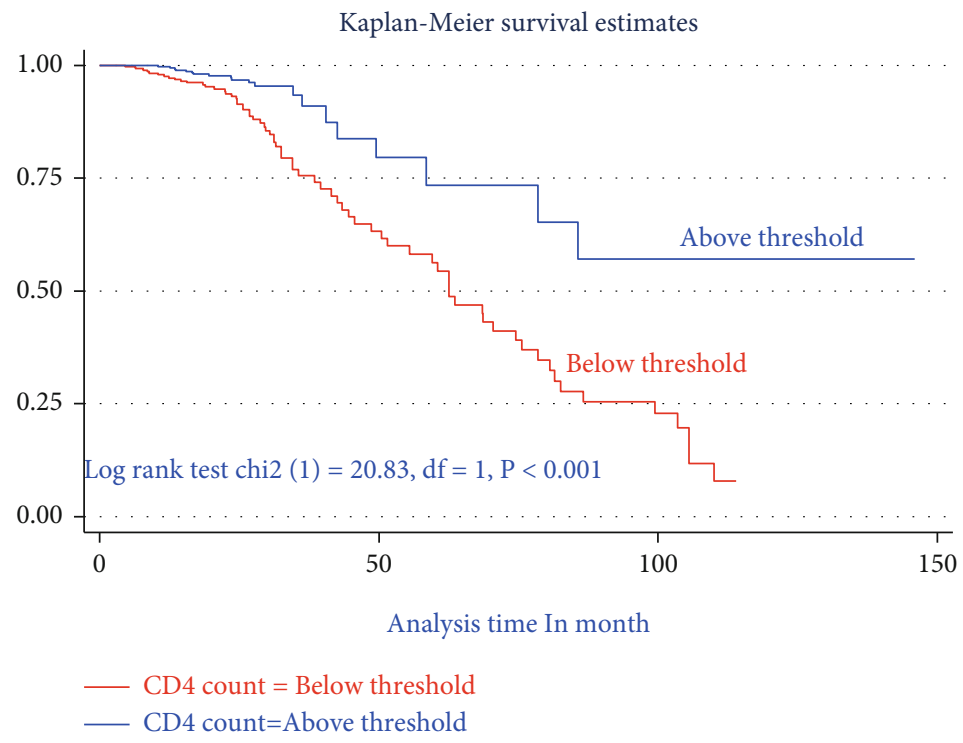

FIgure 2: The Kaplan-Meier failure estimate curves to compare the hazard of death for HIV-positive children on ART with different categories of CD4 count in the selected public health facilities in Northwest Ethiopia, January 1, 2009-December 30, 2020.

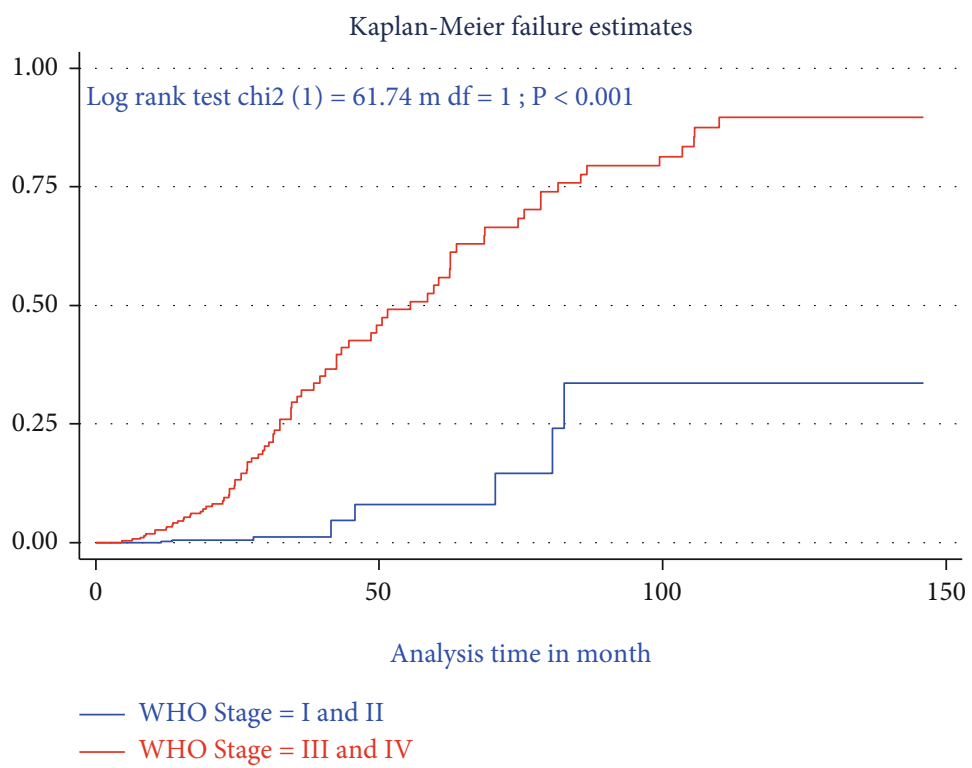

FIgURE 3: The Kaplan-Meier failure estimate curves to compare hazard of death for HIV-positive children on ART with different categories of WHO clinical stages in the selected public health facilities in Northwest Ethiopia, January 1, 2009-December 30, 2020.

100 child-years (95\% CI: 3.6, 5.8), which is consistent with findings from the Felege Hiwot Comprehensive Specialized Hospital, Northwest Ethiopia (four deaths per 100 childyears) [37] and Northwest Ethiopia 4.4 per 100 child-years (95\% CI: 3.2, 6.0) [13]. However, the mortality rate reported in this study is higher than studies reported from Mekelle Hospital, Northern Ethiopia (1.4 deaths per 100 child-years) [38], Wolaita Zone health facilities, Southern Ethiopia (2.1 deaths per 100 child-years) [39], Northwest Ethiopia (3.2 deaths per 100 child-years [29], the Asia-Pacific region (1.9 deaths per 100 child-years) [40], Zimbabwe (2.9 deaths per 100 child-years) [41], and Congo (3.4 deaths per 100 childyears) [42]. Conversely, the mortality rate found in this study is much lower than that of Debre Tabor General Hospital and Dessie Referral Hospital (6.3 deaths per 100 childyears) [38], Addis Ababa (8.8 deaths per 100 child-years) [13], Southwest Ethiopia (11.2 deaths per 1000 personyears) [11], and Kenya (8.4 deaths per 100 child-years) [43]. Explanations for variation in the incidence of mortality rate might be due to the difference in health care awareness of the community, sample size, study settings, study period, and/or characteristics of study participants. The present study explored predictors of mortality among study participants. In this study, children who had CD4 counts below the threshold showed a higher risk of death than their counterparts. This finding is consistent with other previous 
TABLE 4: Bivariable and multivariate Cox regression for predictors of mortality of undernourished HIV-positive children among selected health facility of Northwest Ethiopia 2009-2020.

\begin{tabular}{|c|c|c|c|c|c|}
\hline \multirow{2}{*}{ Variables } & \multirow{2}{*}{ Categories } & \multicolumn{2}{|c|}{ Survival status } & \multirow{2}{*}{ CHR (95\% CI) } & \multirow{2}{*}{ AHR (95\% CI) } \\
\hline & & Died & Censored & & \\
\hline \multirow{2}{*}{ Sex } & Male & 35 & 302 & 1 & 1 \\
\hline & Female & 56 & 328 & $1.3(0.88,2.07)$ & $1.7(0.70,1.70)$ \\
\hline \multirow{3}{*}{ Age } & $\leq 60$ months & 29 & 49 & $2.8(1.70,4.60)$ & $1.7(0.79,3.20)$ \\
\hline & $61-120$ months & 23 & 231 & $1.2(0.79,2.11)$ & $2.5(0.93,4.50)$ \\
\hline & $\geq 121$ months & 38 & 351 & 1 & 1 \\
\hline \multirow{2}{*}{ Residence } & Urban & 61 & 449 & $1.16(0.73,1.87)$ & $1.12(0.7,1.85)$ \\
\hline & Rural & 29 & 182 & 1 & 1 \\
\hline \multirow{2}{*}{ CD4 count } & Below threshold & 70 & 238 & $3.12(1.90,7.20)$ & $1.6(1.19,7.85)^{*}$ \\
\hline & Above threshold & 20 & 393 & 1 & 1 \\
\hline \multirow{2}{*}{ WHO stage } & Stages I and II & 8 & 435 & 1 & 1 \\
\hline & Stages III and IV & 82 & 196 & $10.9(5.20,22.70)$ & $4.5(2.80,8.40)^{*}$ \\
\hline \multirow{2}{*}{ Adherence } & Optimal adherence & 21 & 489 & 1 & 1 \\
\hline & Suboptimal adherence & 69 & 142 & $6.3(3.80,10.30)$ & $1.8(0.60,3.60)$ \\
\hline \multirow{2}{*}{ Dietary counseling } & Yes & 44 & 421 & 1 & 1 \\
\hline & No & 46 & 210 & $1.8(1.50,2.50)$ & $1.9(0.50,1.50)$ \\
\hline \multirow{2}{*}{ Disclosure status } & Yes & 54 & 104 & $3.3(2.30,5.10)$ & $1.7(0.59,2.8)$ \\
\hline & No & 36 & 527 & 1 & 1 \\
\hline \multirow{3}{*}{ Duration of follow-up } & $\leq 36$ months & 6 & 217 & 1 & 1 \\
\hline & $37-72$ months & 19 & 276 & $2.1(0.90,5.10)$ & $2.1(0.70,5.70)$ \\
\hline & $>72$ months & 65 & 138 & $7.1(3.10,16.30)$ & $2.6(0.80,3.60)$ \\
\hline \multirow{3}{*}{ Wasting } & Normal & 70 & 461 & 1 & 1 \\
\hline & Moderate $(\mathrm{WHZ}$ or $\mathrm{BAZ}<-2)$ & 18 & 101 & $9.6(1.28,12.6)$ & $0.8(0.18,4.30)$ \\
\hline & Severe $(\mathrm{WHZ}$ or BAZ $<-3)$ & 2 & 69 & $7.8(1.80,16.30)$ & $1.07(0.50,1.90)$ \\
\hline \multirow{3}{*}{ Underweight } & Normal & 34 & 457 & 1 & 1 \\
\hline & Moderate $(\mathrm{WAZ}<-2)$ & 18 & 126 & $1.6(0.91,2.91)$ & $0.6(0.30,1.17)$ \\
\hline & Severe $(\mathrm{WAZ}<-3)$ & 38 & 48 & $2.9(1.80,4.82)$ & $1.2(0.60,2.1)$ \\
\hline \multirow{3}{*}{ Stunting } & Normal & 18 & 410 & 1 & 1 \\
\hline & Moderate $(\mathrm{HAZ}<-2)$ & 29 & 125 & $5.6(2.50,8.40)$ & $1.6(0.80,3.20)$ \\
\hline & Severe $($ HAZ < -3) & 43 & 96 & $4.6(3.20,9.90)$ & $2.9(1.80,6.40)^{*}$ \\
\hline \multirow{2}{*}{ MUAC } & $\leq 11.5 \mathrm{~cm}$ & 56 & 214 & $4.5(2.10,6.10)$ & $1.5(0.60,4.20)$ \\
\hline & $>11.5 \mathrm{~cm}$ & 34 & 417 & 1 & 1 \\
\hline \multirow{2}{*}{$\mathrm{CPT}$} & Yes & 17 & 402 & 1 & 1 \\
\hline & No & 73 & 229 & $2.5(1.60,7.60)$ & $1.2(0.43,4.50)$ \\
\hline \multirow{2}{*}{ SAM admission history } & Yes & 37 & 91 & $2.8(1.80,4.30)$ & $1.7(0.60,2.90)$ \\
\hline & No & 53 & 540 & 1 & 1 \\
\hline
\end{tabular}

$\mathrm{CHR}=$ crude hazard ratio; $\mathrm{AHR}=$ adjusted hazard ratio; $\mathrm{CI}=$ confidence interval; 1 = reference category. ${ }^{*}$ Significant predictors variables on final the multivariable models at $P<0.05$.

studies conducted in Ethiopia [11, 18, 19, 29, 37, 44], India [45], Congo [42], Tanzania [46], Bangladesh [47], and Malaysia [48], which all indicate that low CD4 count was an independent predictor of mortality. Serious and lifethreatening opportunistic infections, such as central nervous system toxoplasmosis and cryptococcal meningitis, are more common in children with severe immunodeficiency. This hastened a sharp reduction in CD4 count; this has declined the survival probability of children since care started. Advanced WHO HIV clinical staging (III and IV) was another strong predictor of mortality. Children with advanced WHO HIV clinical stage (III and IV) at the time of ART initiation have a higher risk of death as compared to their counterparts with mild status (i.e., WHO HIV clinical disease stage (I and II)). Similar results were reported from previous studies conducted in Ethiopia $[8,37,49,50]$, two rural hospitals in South Africa [5], Tanzania [38], Zimbabwe [41], Kenya [43], Eastern India [45], and Malawi [51], which all indicated that advanced WHO HIV clinical disease stages were a predictor of mortality. For those living with HIV, as WHO HIV clinical staging becomes more advanced, the risk of developing and recurrence of opportunistic 
infection also increases, which might be associated with the cause of death.

In this study, severe stunting was also an independent predictor of mortality among HIV-positive children on ART. Children who were severely stunted before ART initiation have a higher risk of death as compared to those who were not stunted. This is consistent with findings in Northwest Ethiopia [13], Burkina Faso [4], and Tanzania [22]. Reasonably, malnutrition is a common complication of HIV infection. Severe stunting is associated with a weakened immune system and complicates the treatment of diseases by affecting intestinal absorption of drugs and the ability to absorb various nutrients, besides causing dysregulated lipid metabolism and increased proteolysis in the body $[1,8,46]$.

\section{Limitations of the Study}

There were inconsistencies in determining causes of death in this study, particularly for individuals who died at home. Some of those who died without being notified may have been counted as "lost to follow-up." In addition, important determinants of death, such as viral load and nutritional deficiencies, were also not taken into account.

\section{Conclusion}

The findings of the current study indicated that HIVpositive children on ART had a high rate of mortality. In this study, nutritional status was found to have a significant effect on the survival of HIV-positive children on ART. Baseline CD4 counts of less than the threshold, advanced WHO HIV clinical disease staging (III and IV), and severe stunting were found to be independent predictors of mortality in HIV children on ART. This calls for the government to give due attention to strengthening HIV/AIDS treatment and care modalities and ensure that the relevant nutritional support for children at risk is provided appropriately.

\author{
Abbreviations \\ ART: Antiretroviral therapy \\ AIDS: Acquired immunodeficiency syndrome \\ HAZ: Height for age $\mathrm{Z}$ score \\ HIV: Human immunodeficiency virus \\ SAM: Severe acute malnutrition \\ WAZ: Weight for age $\mathrm{Z}$ score \\ WHO: World Health Organization \\ WHZ: Weight for height $\mathrm{Z}$ score.
}

\section{Data Availability}

All relevant data were within the corresponding author upon reasonable request.

\section{Ethical Approval}

An ethical clearance letter Debre amrkose university (reference number: DMU -IRB-984/119/11) was obtained from the research institute review board (IRB) of Debre Markos University. The ethics committee formally waived the need for formal written consent for peadtrice patients and from their care giver since the study was done through retrospective reviews of patient charts.

\section{Conflicts of Interest}

The authors declared no potential conflicts of interest concerning the research, authorship, and/or publication of this article.

\section{Authors' Contributions}

FK conceived the research idea, study design, data collection, analysis, interpretation, and manuscript write-up. TK, $\mathrm{AH}$, and MM carried out data collection, analysis, interpretation, and manuscript write-up. All authors have read and approved the final manuscript.

\section{Acknowledgments}

The authors would like to acknowledge the health institutions' administrative staff.

\section{References}

[1] D. W. Daka and M. S. Ergiba, "Prevalence of malnutrition and associated factors among adult patients on antiretroviral therapy follow-up care in Jimma Medical Center, Southwest Ethiopia," PLoS One, vol. 15, no. 3, article e0229883, 2020.

[2] M. Teshome, A. A. Hambisa, and Y. Dessie, "Determinants of mortality among HIV positives after initiating antiretroviral therapy in western Ethiopia: a hospital-based retrospective cohort study," vol. 2013, ISRN AIDS, 2013.

[3] WHO, Guideline Updates on the Management of Severe Acute Malnutrition in Infants and Children, WHO, 2013.

[4] L. G. Savadogo, P. Donnen, E. Kafando, P. Hennart, and M. Dramaix, "Impact of HIV/AIDS on mortality and nutritional recovery among hospitalized severely malnourished children before starting antiretroviral treatment," Open Journal of Pediatrics, vol. 3, no. 4, pp. 340-345, 2013.

[5] M. Muzigaba and D. Sanders, "The impact of HIV infection and disease stage on the rate of weight gain and duration of refeeding and treatment in severely malnourished children in rural South African hospitals," Research, vol. 11, no. 2, p. 86, 2017.

[6] N. W. Berhe, M. W. Gebremedhin, and K. H. Misgina, "Psychosocial correlates of nutritional status among people living with HIV on antiretroviral therapy: a matched case-control study in Central zone of Tigray, Northern Ethiopia," PLoS One, vol. 12, no. 3, 2017.

[7] M. Muenchhoff, M. Healy, R. Singh et al., "Malnutrition in HIV-infected children is an indicator of severe disease with an impaired response to antiretroviral therapy," AIDS Research and Human Retroviruses, vol. 34, no. 1, pp. 46-55, 2018.

[8] D. Y. Gebremichael, K. T. Hadush, E. M. Kebede, and R. T. Zegeye, "Food insecurity, nutritional status, and factors associated with malnutrition among people living with HIV/AIDS attending antiretroviral therapy at public health facilities in West Shewa zone, Central Ethiopia," BioMed Research International, vol. 2018, Article ID 1913534, 9 pages, 2018. 
[9] A. N. Tekelehaimanot, T. B. Lemma, E. K. Gudina, M. Getnet, D. Amdisa, and L. S. Dadi, "Predictors of Under Nutrition and its implication toward HIV continuum care among adult people living with HIV in Jimma zone public hospitals, Southwest Ethiopia: a Mixed Method study," Journal of the International Association of Providers of AIDS Care, vol. 19, 2020.

[10] C. I. Penda, E. C. Eboumbou Moukoko, N. P. Nolla, O. N. Evindi Abomo, and P. Koki Ndombo, "Malnutrition among HIV infected children under 5 years of age at the Laquintinie hospital Douala, Cameroon," Pan African Medical Journal, vol. 30, no. 91, p. 91, 2018.

[11] A. Oumer, M. E. Kubsa, and B. A. Mekonnen, "Malnutrition as predictor of survival from anti-retroviral treatment among children living with HIV/AIDS in Southwest Ethiopia: survival analysis," BMC Pediatrics, vol. 19, no. 1, p. 474, 2019.

[12] M. Fontana, G. Zuin, A. Plebani, K. Bastoni, G. Visconti, and N. Principi, "Body composition in HIV-infected children: relations with disease progression and survival," The American Journal of Clinical Nutrition, vol. 69, no. 6, pp. 1282-1286, 1999.

[13] A. Alebel, F. Wagnew, C. Tesema, G. D. Kibret, P. Petrucka, and S. Eshite, "Effects of undernutrition on survival of human immunodeficiency virus positive children on antiretroviral therapy," Italian Journal of Pediatrics, vol. 44, no. 1, p. 29 , 2018.

[14] Y. T. Hibstie, G. D. Kibret, A. Talie, B. Temesgen, M. W. Melkamu, and A. Alebel, "Nearly one in every six HIV-infected children lost from ART follow-up at Debre Markos referral hospital, Northwest Ethiopia: a 14-year retrospective followup study," PLoS One, vol. 15, no. 9, article e0239013, 2020.

[15] M. B. Getahun, G. S. Teshome, F. A. Fenta, A. D. Bizuneh, G. B. Mulu, and M. A. Kebede, "Determinants of severe acute malnutrition among HIV-positive children receiving HAART in public health institutions of North Wollo zone, Northeastern Ethiopia: unmatched case-control study," Pediatric Health, Medicine and Therapeutics, vol. 11, pp. 313-321, 2020.

[16] G. B. Gonzales, J. M. Njunge, B. M. Gichuki et al., "Plasma proteomics reveals markers of metabolic stress in HIV infected children with severe acute malnutrition," Scientific Reports, vol. 10, no. 1, p. 11235, 2020.

[17] L. Nicholson, M. Chisenga, J. Siame, L. Kasonka, and S. Filteau, "Growth and health outcomes at school age in HIV-exposed, uninfected Zambian children: follow-up of two cohorts studied in infancy," BMC Pediatrics, vol. 15, no. 1, p. 66, 2015.

[18] M. Daniel, "Nutritional status and associated factors among adult HIV/AIDS clients in Felege Hiwot referral hospital, Bahir Dar, Ethiopia," Science Journal of Public Health, vol. 1, no. 1, p. 24, 2013.

[19] T. H. Gebru, H. H. Mekonen, and K. G. Kiros, "Undernutrition and associated factors among adult HIV/AIDS patients receiving antiretroviral therapy in the eastern zone of Tigray, Northern Ethiopia: a cross-sectional study," Archives of Public Health, vol. 78, 2020.

[20] W. Tesfay, M. Abay, S. Hintsa, and T. Zafu, "Length of stay to recover from severe acute malnutrition and associated factors among under-five years children admitted to public hospitals in Aksum, Ethiopia," PLoS One, vol. 15, no. 9, article e0238311, 2020.

[21] Sphere, "The Sphere handbook of humanitarian charter and minimum standards in humanitarian response," 2021.

[22] B. F. Sunguya, K. C. Poudel, L. B. Mlunde, D. P. Urassa, J. Yasuoka, and M. Jimba, "Poor nutrition status and associ- ated feeding practices among HIV-positive children in a food secure region in Tanzania: a call for tailored nutrition training," PLoS One, vol. 9, no. 5, article e98308, 2014.

[23] FMOH, National Consolidated Guidelines for Comprehensive HIV Prevention, Care and Treatment, World Health Organization, 2021.

[24] R. C. Vreeman, M. L. Scanlon, M. S. McHenry, and W. M. Nyandiko, "The physical and psychological effects of HIV infection and its treatment on perinatally HIV-infected children," Journal of the International AIDS Society, vol. 18, Supplement 6, 2015.

[25] A. M. Tekleab, B. T. Tadesse, A. Z. Giref, D. Shimelis, and M. Gebre, "Anthropometric improvement among HIV infected pre-school children following initiation of first line anti-retroviral therapy: implications for follow up," PLoS One, vol. 11, no. 12, article e0167565, 2016.

[26] O. I. Ekwunife, H. G. Woldie, and D. B. Ketema, "Predictors of recovery rate among undernourished HIV-positive adults treated with ready-to-use therapeutic food at Debre Markos comprehensive specialized hospital: a retrospective cohort study," PLoS One, vol. 16, no. 8, article e0167565, 2021.

[27] G. Arage, T. Worku, and A. Semahegn, "Survival rate of HIVinfected children after initiation of the antiretroviral therapy and its predictors in Ethiopia: a facility-based retrospective cohort," SAGE Open Medicine, vol. 7, 2019.

[28] I. Trehan, B. A. O'Hare, A. Phiri, and G. T. Heikens, "Challenges in the Management of HIV-Infected Malnourished Children in Sub- Saharan Africa," AIDS Research and Treatment, vol. 2012, Article ID 790786, 8 pages, 2012.

[29] A. Alebel, E. H. Engeda, M. M. Kelkay et al., "mortality rate among HIV-positive children on ART in Northwest Ethiopia: a historical cohort study," BMC Public Health, vol. 20, no. 1, p. 1303, 2020.

[30] F. B. Kebede and J. A. Abebe, "Time to develop pulmonary tuberculosis and predictors among HIV infected children receiving anti-retroviral therapy in Assosa and Pawe general hospitals, Northwest Ethiopia: a retrospective cohort study," Journal of Pulmonary \& Respiratory Medicine, vol. 10, no. 7, 2020.

[31] D. F. Moore, Applied Survival Analysis Using R. Piscataway, Springer Nature, 2015.

[32] B. A. Yihun, G. D. Kibret, and C. T. Leshargie, "Incidence and predictors of treatment failure among children on first-line antiretroviral therapy in Amhara region referral hospitals, Northwest Ethiopia 2018: a retrospective study," PLoS One, vol. 14, no. 5, article e0215300, 2019.

[33] WHO, Updates on the Management of Severe Acute Malnutrition in Infants and Children, World Health Organization, Guideline, Geneva, Switzerland, 2013.

[34] Guidelines for Paediatric HIVIAIDS Care and Treatment in Ethiopia, Federal HIVIAIDS Prevention and Control Office Federal Ministry of Health, July 2007, 2021.

[35] FMOH, National Guidelines for Comprehensive HIV Prevention, Care and Treatment, 2017.

[36] Ethiopian Ministry of Science and Technology, Ethiopian National-Research-Ethics-Review-Guideline, Federal Ministry of Health of Ethiopia, 2014.

[37] D. N. Koye, T. A. Ayele, and B. M. Zeleke, "Predictors of mortality among children on antiretroviral therapy at a referral 
hospital, Northwest Ethiopia: a retrospective follow up study," BMC Pediatrics, vol. 12, no. 1, 2012.

[38] A. Gebremedhin, S. Gebremariam, F. Haile, B. Weldearegawi, and C. Decotelli, "Predictors of mortality among HIV infected children on antiretroviral therapy in Mekelle hospital, Northern Ethiopia: a retrospective cohort study," BMC Public Health, vol. 13, no. 1, 2013.

[39] B. Shimelash, Assessment of the Effect of Malnutrition on Survival of HIV Infected Children after Initiation of Antiretroviral Treatment in Wolaita Zone Health Facilities, SNNPR, Ethiopia, [M.S. thesis], Addis Ababa University, 2014.

[40] P. Lumbiganon, A. Kariminia, L. Aurpibul et al., "Survival of HIV-infected children: a cohort study from the Asia-Pacific region," Journal of Acquired Immune Deficiency Syndromes, vol. 56, no. 4, pp. 365-371, 2011.

[41] A. E. Njom Nlend and A. B. Loussikila, "Predictors of mortality among HIV-infected children receiving highly active antiretroviral therapy," Médecine et Maladies Infectieuses, vol. 47, no. 1, pp. 32-37, 2017.

[42] J. Nugent, A. Edmonds, J. Lusiama, D. Thompson, and F. Behets, "Predicting mortality in HIV-infected children initiating highly active antiretroviral therapy in a resourcedeprived setting," The Pediatric Infectious Disease Journal, vol. 33, no. 11, pp. 1148-1155, 2014.

[43] D. C. Wamalwa, E. M. Obimbo, C. Farquhar et al., "Predictors of mortality in HIV-1 infected children on antiretroviral therapy in Kenya: a prospective cohort," BMC Pediatrics, vol. 10, no. $1,2010$.

[44] B. Taye, S. Shiferaw, and F. Enquselassie, "The impact of malnutrition in survival of HIV infected children after initiation of antiretroviral treatment (ART)," Ethiopian Medical Journal, vol. 48, no. 1, pp. 1-10, 2010.

[45] A. Bhowmik, S. Bhandari, R. De, and S. K. Guha, "Predictors of mortality among HIV-infected patients initiating anti retroviral therapy at a tertiary care hospital in Eastern India," Asian Pacific Journal of Tropical Medicine, vol. 5, no. 12, pp. 986990, 2012.

[46] R. S. Mwiru, D. Spiegelman, C. Duggan et al., "Nutritional status and other baseline predictors of mortality among HIVinfected children initiating antiretroviral therapy in Tanzania," Journal of the International Association of Providers of AIDS Care, vol. 14, no. 2, pp. 172-179, 2015.

[47] L. Shahrin, D. T. Leung, N. Matin et al., "Characteristics and predictors of death among hospitalized HIV-infected patients in a low HIV prevalence country: Bangladesh," PLoS One, vol. 9, no. 12, article e113095, 2014.

[48] F. S. Moy, P. Fahey, N. K. Nik Yusoff, K. A. Razali, R. Nallusamy, and the TREAT Asia Pediatric HIV Observational Database (TApHOD), "Outcomes of human immunodeficiency virus-infected children after anti-retroviral therapy in Malaysia," Journal of Paediatrics and Child Health, vol. 51, no. 2, pp. 204-208, 2015.

[49] A. A. Kedir, A. Desta, and G. Fesseha, "Factors affecting survival of HIV positive children taking antiretroviral therapy at Adama Referral Hospital and Medical College, Ethiopia," Journal of AIDS and Clinical Research, vol. 5, no. 3, 2014.

[50] G. Ebissa, N. Deyessa, and S. Biadgilign, "Predictors of early mortality in a cohort of HIV-infected children receiving high active antiretroviral treatment in public hospitals in Ethiopia," AIDS Care, vol. 27, no. 6, pp. 723-730, 2015.
[51] W. C. Buck, D. Olson, M. Kabue et al., "Risk factors for mortality in Malawian children with human immunodeficiency virus and tuberculosis co-infection," The International Journal of Tuberculosis and Lung Disease, vol. 17, no. 11, pp. 13891395, 2013. 